\title{
Türkiye'de Kullanılan Plastik Besin Kaplarnnn Toksikoloji Açısından Değerlendirilmesi
}

Toxicological Assessment of Plastic Food Containers Used in Turkey

\section{Nevin VURAL*}

Polimer bilimi ve teknolojisinin 1902 de ilk tam sentetik plastik madde olan Novolak'ın (1) yapımından sonra büyük bir hızla gelişimi, bu insan yapısı bileşiklerin geniş ölçüde kullanılmasına yol açmıştır. $\mathrm{Bu}$ gün plastik maddeler günlük yaşantımızın, endüstrinin ve tıbbın her alanında yer almıştır. Geçmişte bu dev moleküllü bileşikler, araştırıcıları daha çok kullanma yerlerine göre kimyasal, fiziksel ve mekanik özelliklerini geliştirme açısından ilgilendiriyordu. Ancak bunların gittikçe artan miktar ve alanda kullanılmaları insan sağlığı bakımından bazı sorunlara ve bu nedenle de plastik maddelerin toksikolojik araştırmalarına daha çok önem verilmesi zorunluluğunu ortaya çıkarmıştır $(2,3)$.

Plastik maddelerin doğrudan doğruya insan ve hayvan organizması ile temasta olması sonucu ortaya çıkan toksik etkiler $(4,5)$, farmasötik preparatların plastik maddelerle olan etkileşmeleri $(6,7)$, plastiklerin ısı ve ışı etkisi ile parçalanmaları (fotodegradasyon, termodegradasyon) ve yanmaları sonucu oluşan toksik maddeler (8, 9,10 ), besin maddeleri ile temaslarından ortaya çıkan toksikolojik ve hijyenik sorunlar $(3,11)$ ve plastik yapımında çalışan kimselerin çeşitli plastik ana ve yardımcı maddelerine maruz kalmaları ile ilgili akut ve kronik meslek zehirlenmeleri $(12,13)$ bu toksikolojik sorunların başlıcalarını oluşturmaktadır. Yine son yıllarda plastik fabrikaları ve kullanılmıs plastik artık maddelerinin okyanus, deniz,

Redaksiyona verildiği tarih: 20 Aralık 1977.

* Toksikoloji Kürsüsü, Eczacılık Fakültesi, Ankara Üniversitesi. 
su ve havayı kirletmeleri $(14,15)$, çevre kirlenmesi ve ekoloji bak1mindan büyük önem taşımaktadır.

Plastik maddelerin uzun veya kısa süreli olarak besin maddelerinin ambalajında ve mutfak eşyası olarak yaygın bir şekilde kullanılmaları toplum sağlığını yakından ilgilendiren bir konudur. Bu nedenle plastik içinde kalabilen monomer ve plastik madde yapımında çeşitli amaçlarla kullanılan plastik katkı maddelerinin besin maddelerine geçip geçmediklerini araştırmak ve bunların miktarlarını saptamak, plastik kapların toksisitesi için önemli bir gösterge olmaktadır (16, 17). Bu amaçla dış ülkelerde yapılan bir çok araştırmalara raslanmaktadir (18-22).

Bu araştırmada Türkiye'de besin ambalajı ve kabı olarak kullanılan plastiklerin başlıca hangi polimerlerden oluştuğu ve şekillendirilmiş plastiklerde ağır metaller (kurşun ve kadmiyum), monomer maddeler (stiren ve formaldehit), total ekstraksiyon maddeleri araştırılarak bulguların toksikolojik açıdan değerlendirilmesi amaç edinilmiştir.

DENEL BÖLÜM

MATERYAL

Çalı̧̧mamızda, besin maddelerinin ambalajı ve konulmasında kullanılan hazır plastik maddeler üzerinde durulmuştur. Bu amaçla materyal toplamada şu yöntem uygulanmıştır:

a) Kullanılmamış yeni plastik kaplar Ankara’nın çeşitli pazar ve dükkânlarından satın alınmıştır. Katı, sıvı, yağlı, asitli veya nötral besin maddelerinin konulmasında kullanılan eşyayı (bidon, kavanoz, kâse, yağlık, tabak, tencere, bardak) kapsayacak şekilde örnek toplanmıştır. Diğer taraftan alınan plastik kapların polimer cinsleri hemen laboratuvarımızda saptandığından çeşitli polimerleri içeren numunelerin elde edilmesi sağlanmıştır.

b) Besin maddelerinin içinde uzun süre saklandığı (sıvı yağlar, katı yağlar, tahin, turşu) veya kısa süre bulundurulduğu (yoğurt, meyve suları, hazır yemekler) plastik madde işleyen imalâthanelerden sağlanmıştır.

$\mathrm{Bu}$ amaçla 13 polivinil klorür (PVG), 30 polietilen (10 tanesi alçak yoğunluklu polietilen: ADPE, 13 tanesi yüksek yoğunluklu polietilen: YDPE ve 7 tanesi polietilen enjeksiyon olmak üzere: $P E-I)$, 
23 polistiren (PS), 18 melamin plastik kap örneği materyal olarak toplanmiştır.

Plastik kapların varsa ticari damgası, imalâthane yeri ve standard numaraları da kaydedilmiştir.

\section{YÖNTEM}

\section{Plastik kapların polimer cinslerinin saptanması:}

Araştırmada kullanılan plastik besin kaplarının polimer cinsinin saptanmasinda, FRANGK ve MƯHLSCHLEGEL'in (17) genel standard yöntemleri uygulanmıştır. Bu amaçla örneklerde şekil alabilme, kırılabilirlik, sertlik, sıcaklığa dayanıklık gibi fizik özelliklerle, çözünürlük, yanma ürünleri, alev alma şekli ve elementel analiz gibi kimyasal özellikleri araştırılmıştır. Klor, BEILSTEIN deneyi (17) ile, azot ise LASSAIGNE deneyi (23) ile aranmıştır. Bu şekilde polimer sinıfi saptanan plastik örnekleri Petro Kimya Gebze Araştırma laboratuvarına gönderilmiş ve böylece bulgularımızın desteklenmesi sağlanmıştır.

2. Plastiklerde metalik zehirlerin tayini:

Metalik zehirlerden kurşun $(\mathrm{Pb})$ ve kadmiyum (Cd); a) doğrudan doğruya plastik kapta, b) asit ortamda plastik kaptan ekstrakte olan çözeltide atomik absorbsiyon spektrofotometresi yöntemi ile tayin edilmiştir.

a) Plastik maddede $\mathrm{Pb}$ ve $\mathrm{Cd}$ tayini için önce kuru külleştirme yapılmıştır. Bunun için DRUCHMAN'ın (24) poliolefin ve polistiren polimerlerinde atomik absorbsiyon yöntemi ile metal aranması için uyguladığı kuru külleştirme işlemi bazı ayrılıklarla uygulanmıştır. Şöyle ki: $(2-5 \pm 0.001 \mathrm{~g})$ numune kvartz krozede Bunzen beki alevinde dikkatle yavaş yavaş kül edilmiş ve $\% 1$ lik $\mathrm{HNO}_{3}$ içinde çözülerek, yine $\% 1$ lik $\mathrm{HNO}_{3}$ ile $10 \mathrm{ml}$ ye tamamlanmıştır. Yöntem kontrolü (recovery) için 2 ve 5 mikrogram ( $\mu \mathrm{g})$ kurşun; 0,5 ve $1 \mu \mathrm{g}$ kadmiyum katılmış saf polimerlerle aynı külleştirme işlemi uygulanmıştır. Çözeltideki $\mathrm{Pb}$ ve Cd'un absorbsiyonları atomik absorbsiyon spektrofotometresinde okunmuş ve değerlendirme standard numunelerle $(0-5 \mu \mathrm{g} \mathrm{Pb} / \mathrm{ml}$ ve $0-0,5 \mu \mathrm{g} \mathrm{Cd} / \mathrm{ml})$ çizilen grafikten yapılmıştır.

b) Plastik kaptan asit ortamda ekstrakte edilen $\mathrm{Pb}$ ve Cd'un saptanması için, \% 4 lük asetik asit çözeltisi kullanılmıştır. Asit 
konsantrasyonu seçiminde İsviçre gida maddeleri tüzüğü (25) uygun görülmüştür. Plastik besin kabı numuneleri asetik asit çözeltisi ile doldurularak oda sıcaklığında 24 saat bekletilmiştir. Bu çözeltilerden $100 \mathrm{ml}$ örnekler bir kaç ml ye kadar deriştirildikten sonra \% $1 \mathrm{HNO}_{3}$ ile $10 \mathrm{ml}$ ye tamamlanmıştır. Atomik absorbsiyon spektrofotometresinde $\mathrm{Pb}$ ve $\mathrm{Cd}$ miktarları tayin edilmiştir. Bu amaçla kullandığımız cihaz ve çalışma koşulları aşağıda belirtilmiştir:

$\begin{aligned} & \text { Aparey: Atomik Absorbsiyon Spektrofotometresi } \\ & \text { Varian Techtron, Model } 1200 \\ & \text { Pb için çalışma koşulları: } \text { Slit } 1.0 \mathrm{~nm} \text { (nanometre) } \\ & \text { Dalga boyu: } 217.0 \mathrm{~nm} \\ & \text { Yakıt: hava-asetilen } \\ & \text { Alev stökiyometresi: oksitleyici } \\ & \text { Lamba akımı: } 6 \mathrm{~mA} \\ & \text { Gd için çalışma koşulları: } \text { Slit } 0.5 \mathrm{~nm} \\ & \text { Dalga boyu: } 228.8 \mathrm{~nm} \\ & \text { Yakıt: hava-asetilen } \\ & \text { Alev stökiyometresi: oksitleyici } \\ & \text { Lamba akımı: } 3 \mathrm{~mA}\end{aligned}$

Standard $\mathrm{Pb}$ ve $\mathrm{Cd}$ çözeltileri, $1 \mathrm{mg} / \mathrm{ml}$ (BDH firması) metal içeren stok standard çözeltinin deiyonize su ile seyreltilmesinden hazırlanmıştır.

3. Plastiklerde monomerlerin tayini:

$\mathrm{Bu}$ amaçla polistiren örneklerinde stiren, melamin plastiklerinde formaldehit aranmıştır.

a) Polistiren plastik kaplarında stiren aranması ve tayini için gaz kromatografisi yöntemi uygulanmıştır (16). Çözücü olarak kloroform kullanılmıştır (26). Çalışma koşulları:

\footnotetext{
Gaz kromatografisi : Packard Gas Chromatograph, Model 7300/7400

Detektör : Alev iyonlaşma detektörü (FID)

Kolon : $5.5 \mathrm{~mm}$ iç çap ve $2 \mathrm{~m}$ uzunlukta cam kolon

Kolon maddesi : \% 20 Carbowax $20 \mathrm{M}$ (stasyoner faz)

Alkali ile muamele görmüş Chromosorb 101 (adsorban)

Sicaklık

: $100^{\circ} \mathrm{C}$ (kolon, enjeksiyon ve detektör) izotermal koşulda

Taşıyıcı gaz : Azot, $82 \mathrm{ml} / \mathrm{dak}$

Alev gazları : Hidrojen $(40 \mathrm{ml} / \mathrm{dk})$, hava $400 \mathrm{ml} / \mathrm{dk}$.

Range Ampere : $10^{-10}$; Electrometer Attenuation: 2

Kâğıt hizı $\quad: 0.5$ inch $/ \mathrm{dk}$.

Enjekte edilen örnek : $1 \mu \mathrm{l}$
} 
Standard stiren çözeltisi, kloroform içinde $\% \quad 0.05$ ve $\% \quad 0.1$ konsantrasyonda hazırlanmıştır. Stiren numunesi Petro Kimya (Pet. Kim.) Gebze Araştırma Md. den sağlanmıştır.

b) Melamin plastiklerinde formaldehit miktarının tayini için, formaldehitin kromotropik asitle verdiği özel renkreaksiyonuna dayanan spektrofotometrik yöntem uygulanmıştır (17). Melamin plastiklerinden nötral ortamda, asit ortamda ( $\% 3$ asetik asit) ve $\%$ 10 etil alkollü ortamda ekstrakte edilen formaldehit tayin edilmiştir. Maksimum absorbsiyon $570 \mathrm{~nm}$ (nanometre) (27) de okunmuştur. Değerlendirme formaldehit standard çözeltisi ile hazırlanan grafikle yapılmıştır. Stok çözelti olarak kullanılan formaldehitin (Merck) miktar tayini Türk Kodeksine göre (28) yapılmış ve standard çözeltiler $(0-15 \mu \mathrm{g} / \mathrm{ml} \mathrm{su})$ formaldehit içerecek şekilde bu derişik formaldehitten uygun seyreltme ile hazırlanmıştır.

Spektrofotometre olarak Beckmann DU-GBT spectrophotometer kullanılmıştır.

4. Plastiklerde total katkı maddelerinin araştırılması:

Polivinil, polistiren ve polietilen plastik besin kapları örneklerinde, etere geçen total katkı maddeleri (plastifiyan, emülsifiyan, stabilizatör gibi) gravimetrik yöntemle tayin edilmiştir. FRANCK ve MÜHSCHLEGEL'den (17) farklı olarak ekstraksiyon oda sicaklığında yapılmıştır. Ekstraktta ayrıca fenol ve türevleri p-nitroanilin ile (29) aranmışır.

\section{BULGULAR}

1. Araştırmada örnek olarak toplanan 84 adet plastik besin kabının polimer cinsine ve temasta olduğu besin maddesine göre sınıflandırılması Tablo I de gösterilmiştir.

2. Plastik kaplarda kurşun ve kadmiyum tayini için kullandığımız atomik absorbsiyon yönteminde duyarlık $\mathrm{Pb}$ için $0.01 \mu \mathrm{g} / \mathrm{ml}$ ve çalışma aralığ $0.00-5.00 \mu \mathrm{g} / \mathrm{ml}$, Cd için ise $0.01 \mu \mathrm{g} / \mathrm{ml}$ duyarlık ve $0.00-0.50 \mu \mathrm{g} / \mathrm{ml}$ çalışma aralığı ile sonuçlar alınabilmiştir. Bu çalışma koşullarına uygun olarak $\mathrm{Pb}$ ve $\mathrm{Cd}$ standardları ile hazırlanan kalibrasyon eğrileri şekil 1 ve şekil 2 de görülmektedir. Polimere ilâve edilmiş $\mathrm{Pb}$ ve $\mathrm{Cd}$ standardları ile verim sıra ile \% 96 ve $\% 98$ olarak saptanmıștir. 
Tablo I. Besin kabi olarak kullanılan

plastiklerin polimer cinsi ve kullanma yerlerine göre sinıflandırılması

\begin{tabular}{|c|c|c|c|c|}
\hline $\begin{array}{l}\text { Polimer cinsine } \\
\text { göre }\end{array}$ & $\begin{array}{l}\text { Örnek } \\
\text { sayısi } \\
(\mathrm{N})\end{array}$ & $\begin{array}{l}\text { Kullanma yerine } \\
\text { göre }\end{array}$ & $\mathrm{N}$ & $\begin{array}{c}\text { Ticari damgasi olanlar } \\
\text { (N) }\end{array}$ \\
\hline $\begin{array}{l}\text { Polietilen (Total) } \\
\text { (PE) }\end{array}$ & 30 & $\begin{array}{l}\text { Içinde uzun süre } \\
\text { besin saklanan (bi- }\end{array}$ & 11 & \multirow{4}{*}{4} \\
\hline YDPE & 13 & tencere) & & \\
\hline ADPE & 10 & $\begin{array}{l}\text { Kisa süre için besin } \\
\text { konanlar tabak, } \\
\text { bardak gibi }\end{array}$ & 15 & \\
\hline PE-Enj. & 7 & Diğer & 4 & \\
\hline $\begin{array}{l}\text { Polistiren (Total) } \\
\text { (PS) }\end{array}$ & 23 & $\begin{array}{l}\text { Uzun süre besinle } \\
\text { edenler (sürahi, ten- } \\
\text { cere, kavanoz, yo- } \\
\text { gurt k.) }\end{array}$ & 11 & \multirow{3}{*}{1} \\
\hline Polimer & 17 & $\begin{array}{l}\text { Kisa süre için besin } \\
\text { konanlar tabak gi- } \\
\text { bi }\end{array}$ & 11 & \\
\hline Antişok & 6 & Diğer & 1 & \\
\hline \multirow[t]{2}{*}{$\begin{array}{l}\text { Polivinil klorür } \\
\text { (Total) (PVG) }\end{array}$} & 13 & $\begin{array}{l}\text { Uzun süre için bes- } \\
\text { sin konanlar (şişe: } \\
\text { sivı yağ için) }\end{array}$ & 10 & \multirow[t]{2}{*}{3} \\
\hline & & Diğer & 3 & \\
\hline \multirow[t]{2}{*}{ Melamin (Total) } & 18 & $\begin{array}{l}\text { Uzun süre besinle } \\
\text { temas edenler (ka- } \\
\text { vanoz, yağllk, ba- } \\
\text { harat için) }\end{array}$ & 4 & \multirow[t]{2}{*}{$\begin{array}{l}18 \text { (12 ayrı } \\
\text { imalâthane) }\end{array}$} \\
\hline & & $\begin{array}{l}\text { Kisa süre besinle te- } \\
\text { mas edenler }\end{array}$ & 14 & \\
\hline
\end{tabular}

Asıl plastik kapta ve asetik asitli çözeltiye geçen metalik zehirlerin miktarları Tablo II de gösterilmiştir. Tabloda ortalama değerler, bulunan maksimum ve minimum değerleri ile standard sapma da görülmektedir.

3. Polistiren plastik kaplarda gaz kromatografisi ile stiren tayini yapılmıştır. Şekil 3-a, 3-b ve 3-c de standard stiren, plastik numune kabinin kloroform ekstraktinin ve (standard stiren + numune ekstraktı) karışımı ile elde edilen kromatogramlar görülmektedir. 


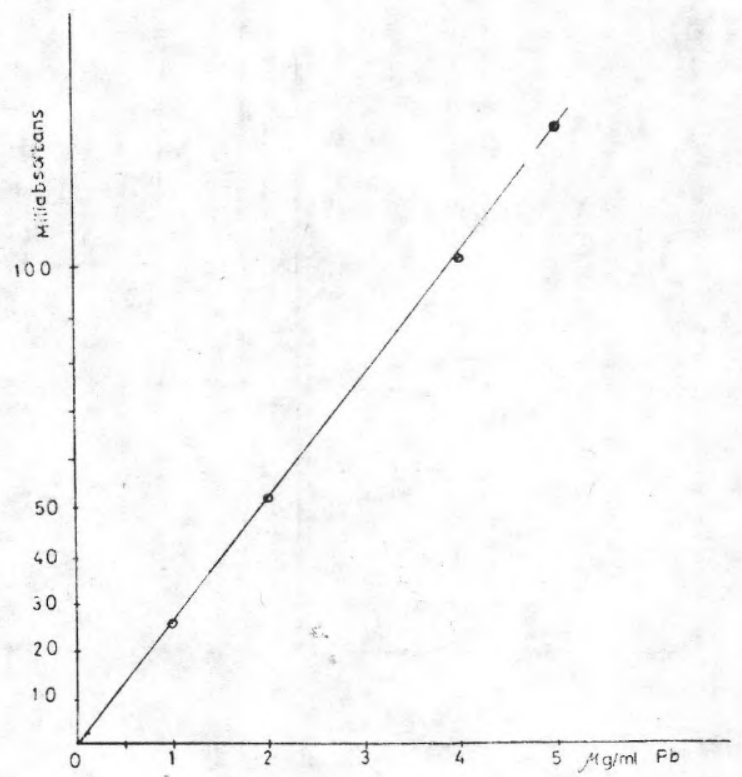

Şek. 1. $0.00-5.00 \mu \mathrm{g} / \mathrm{ml}$ aralığı için $\mathrm{Pb}$ kalibrasyon eğrisi (Atomik absorbsiyon spektrofotometresi ile)

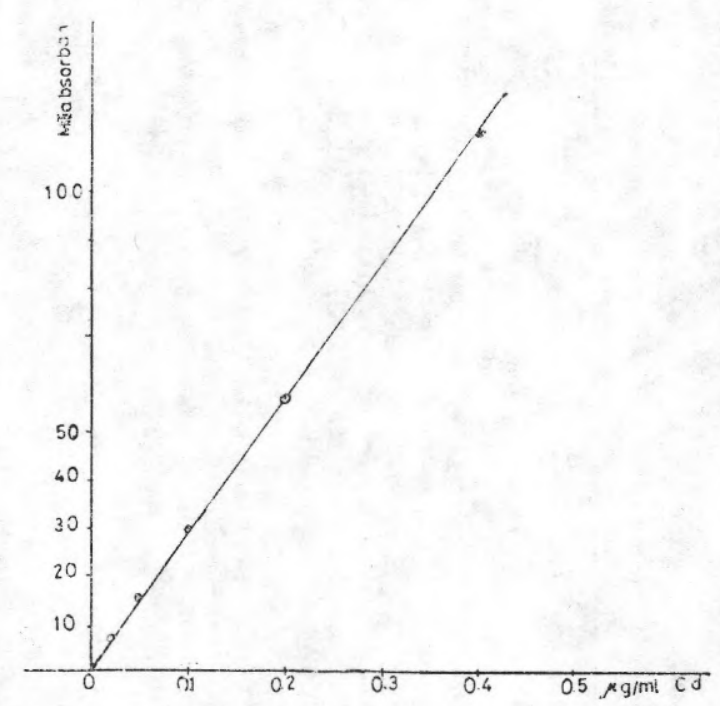

Şek. 2. $0.00-0.50 \mu \mathrm{g} / \mathrm{ml}$ aralığ ${ }_{1}$ için Cd kalibrasyon eğrisi (Atomik absorbsiyon spektrofotometresi ile) 


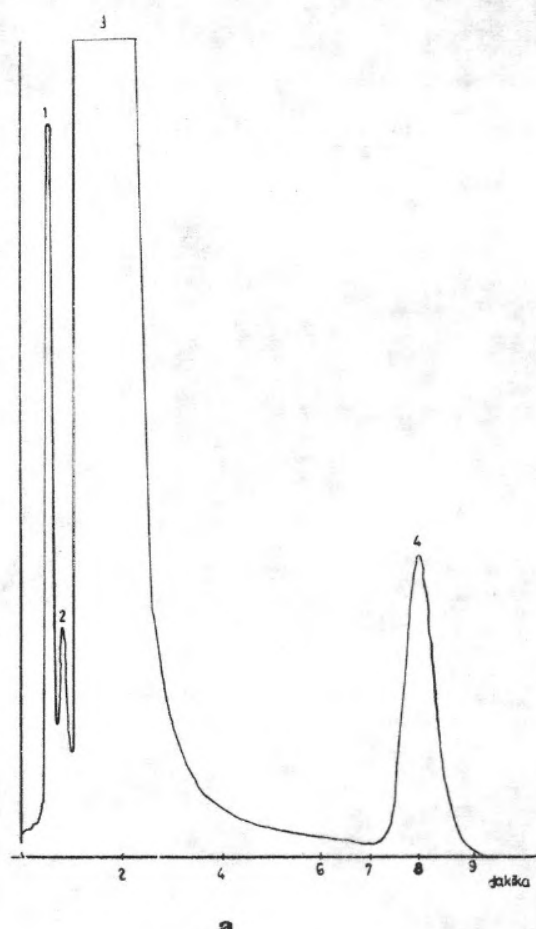

a

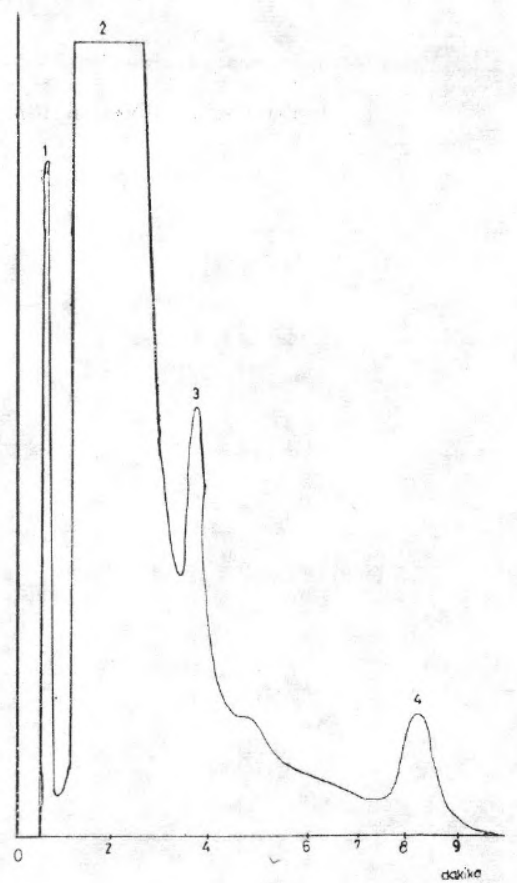

b

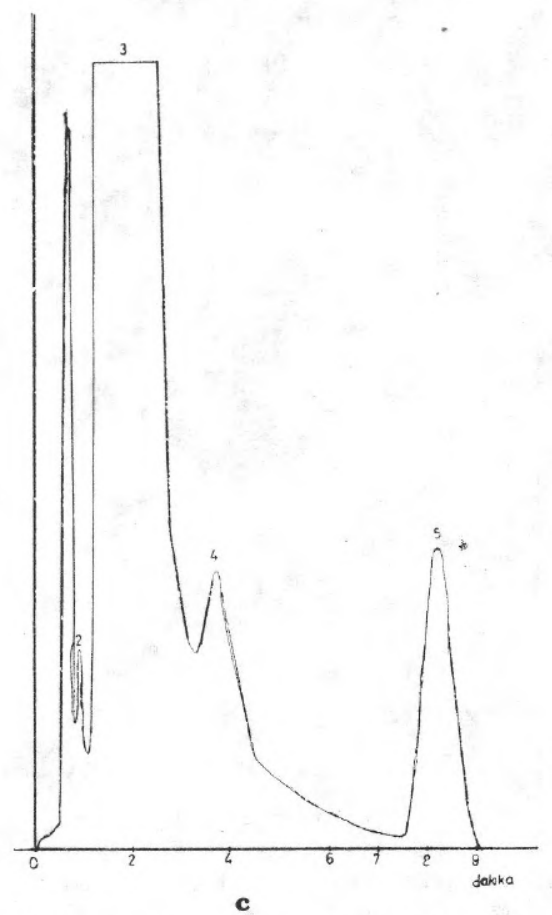

Șek. 3. Carbowax $\mathbf{M}$ üzerinde stirenin gaz kromatografisiyle elde edilen kromatogramı: a) Standard stiren (\% $0.05 \mathrm{mg})$; b) Numune polistirenin $\mathrm{CHCl}_{3}$ daki çözeltisi; c) (Standard + numune) karıșımı. 
Türkiye'de Kullanilan Plastik Besin Kaplarının Toksikoloji...

Tablo II. Plastik kaplarda ve plastik

kaptan asitli çözeltiye geçen $\mathrm{Pb}$ ve $\mathrm{Cd}$ miktarları

\begin{tabular}{|c|c|c|c|c|}
\hline & \multicolumn{2}{|c|}{$\mathrm{Pb}$ miktarı } & \multicolumn{2}{|c|}{ Cd miktarı } \\
\hline $\begin{array}{l}\text { Plastik cinsi } \\
\text { ve örnek sayısı } \\
(\mathrm{N})\end{array}$ & $\begin{array}{l}\text { Plastik } \\
\text { kapta } \\
\% \mu g\end{array}$ & $\begin{array}{c}\% 4 \text { asetik } \\
\text { asite geçen } \\
\mu \mathrm{g} / \mathrm{ml}\end{array}$ & $\begin{array}{l}\text { Plastik } \\
\text { kapta } \\
\% \mu g\end{array}$ & $\begin{array}{c}\% 4 \text { asetik } \\
\text { asite geçen } \\
\mu \mathrm{g} / \mathrm{ml}\end{array}$ \\
\hline $\begin{array}{l}\text { PE (N:14) } \\
\text { Ortalama } \\
\text { Minimum } \\
\text { Maksimum } \\
\text { Standard } \\
\text { sapma (Sd) }\end{array}$ & $\begin{array}{r}270.2 \\
2.5 \\
2600.0 \\
+697.49\end{array}$ & $\begin{array}{r}0.31 \\
0.05 \\
0.40 \\
\pm 0.31\end{array}$ & $\begin{array}{r}26.9 \\
1.8 \\
222.0 \\
\pm 64.86\end{array}$ & $\begin{array}{r}0.06 \\
0.03 \\
0.40 \\
\pm 0.04\end{array}$ \\
\hline \begin{tabular}{l}
\multicolumn{1}{c}{ PS (N:12) } \\
Ortalama \\
Minimum \\
Maksimum \\
Standard \\
sapma (Sd)
\end{tabular} & $\begin{array}{c}218.89 \\
2.0 \\
1550.0 \\
+453.73\end{array}$ & $\begin{array}{c}0.99 \\
0.10 \\
5.0 \\
+1.57\end{array}$ & $\begin{array}{c}31.48 \\
3.8 \\
104.0 \\
+33.09\end{array}$ & $\begin{array}{r}1.1 \\
0.1 \\
2.5 \\
+0.1\end{array}$ \\
\hline
\end{tabular}

Tablo III de ise 16 polistiren plastik kapta tayin edilen stiren bulguları, istatistik değerlendirme ile sunulmuştur.

Tablo III. PS kaplarda stiren miktarı ( $\mathrm{CHCl}_{3}$ 'a geçen)

\begin{tabular}{|c|c|c|}
\hline Numune cinsi ve No. & $\begin{array}{l}\text { Stiren miktarı } \\
\% \mathrm{mg}\end{array}$ & \\
\hline $\left.\begin{array}{l}1 \\
2 \\
3\end{array}\right\}$ sürahi & $\begin{array}{r}850 \\
600 \text { ortalama: } \\
15\end{array}$ & $488.3 \pm 428.55$ \\
\hline $\begin{aligned} 4 & \\
5 & \text { kavanoz } \\
6 & \text { (yoğurt baharat } \\
7 & \text { v.s. için) } \\
8 & \\
9 & \\
10 & \end{aligned}$ & ortalama: & $311.43 \pm 253.73$ \\
\hline $\begin{array}{l}11 \\
12 \\
13 \\
14\end{array} \quad$ tabak tipi & $\begin{array}{r}160 \\
90 \\
25 \\
15\end{array}$ & $72.5 \pm 67.14$ \\
\hline $\begin{array}{l}15 \text { hazır besin maddeleri } \\
16 \text { için (tabak v.s.) }\end{array}$ & ortalama: & $135 \pm 35.36$ \\
\hline$\underset{\mathrm{Sd}}{\operatorname{Ortalama}}(\mathrm{N}: 16)$ & $\begin{array}{r}262.81 \\
\pm 272.65\end{array}$ & \\
\hline
\end{tabular}


4. Melamin plastiklerinde formaldehitin nötr ortamda, asit ortamda ( $\% 3$ asetik asit çözeltisinde) ve alkollü ( $\% 10$ alkol çözeltisi) ortamda geçen miktarları tayin edilmiştir. Şekil 4 de standard formaldehit çözeltisi ile elde edilen kalibrasyon eğrisi görülmektedir. Kromotropik asitle formaldehitin verdiği renk reaksiyonuna dayanan yöntemin duyarlığı $0.5 \mu \mathrm{g} / \mathrm{ml}$ olarak saptanmıştır.

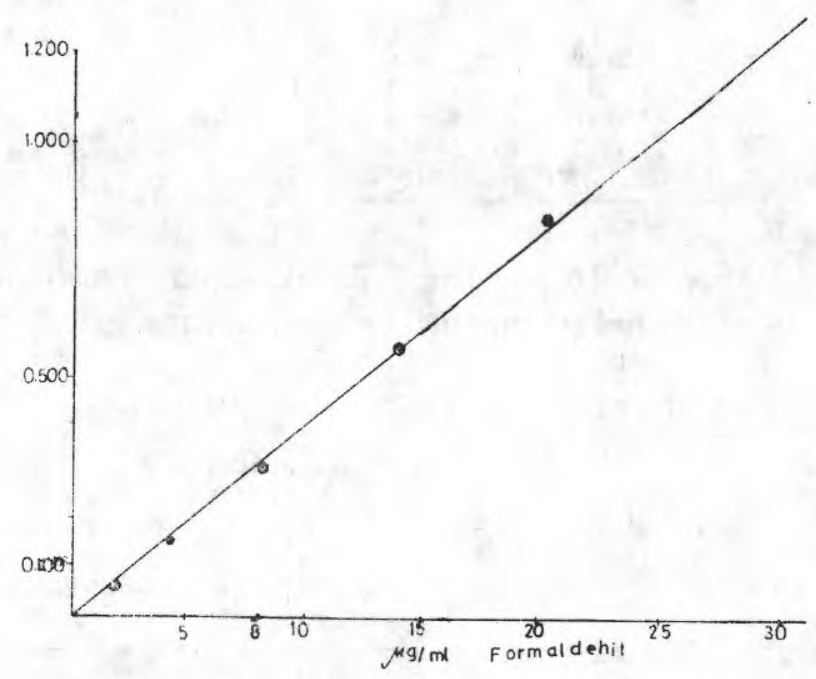

Şekil, 4. Spektofotometrik yöntemle formaldehit kalibrasyon eğrisi (Mak. $\lambda .570 \mathrm{~nm}$ )

Tablo IV de çeşitli melamin plastik besin kaplarında ekstraksiyon çözeltisine geçen formaldehit değerleri gösterilmiştir.

5. Total ekstraksiyon maddeleri özellikle polietilen ve polivinil klorür plastik kaplarında tayin edilmiştir. Bu cins besin kaplarından özellikle yağlı besinle temas edenlerde, total eter ekstraktı saptanmış ve plastifiyan madde olarak fenol ve türevleri aranmıştır. Hepsinde olumlu sonuç alınmıştır. Sonuçlar Tablo V de gösterilmiştir. 
Tablo IV. Nötr, asit ve alkollü ortamda melamin kaplardan geçen formaldehit $\left(\mathrm{CH}_{2} \mathrm{O}\right)$ miktarları* ( $\left.\mu \mathrm{g} / \mathrm{ml}\right)$

\begin{tabular}{|c|c|c|c|c|c|c|c|}
\hline \multirow{2}{*}{\multicolumn{2}{|c|}{$\begin{array}{l}\text { Plastik cinsi ve örnek sayısı } \\
\text { (N) }\end{array}$}} & \multicolumn{2}{|c|}{$\begin{array}{c}\text { Suya geçen } \mathrm{CH}_{2} \mathrm{O} \\
\qquad \mathrm{g} / \mathrm{ml}\end{array}$} & \multicolumn{2}{|c|}{$\begin{array}{c}\% 3 \text { asetik asite } \\
\text { geçen } \mathrm{CH}_{2} \mathrm{O} \mu \mathrm{g} / \mathrm{ml}\end{array}$} & \multicolumn{2}{|c|}{$\begin{array}{l}\% 10 \text { etil alkole } \\
\text { geçen } \mathrm{CH}_{2} \mathrm{O} \mu \mathrm{g} / \mathrm{ml}\end{array}$} \\
\hline & & Oda sıcaklığı & $80^{\circ} \mathrm{C}$ & Oda sıcaklığı & $80^{\circ} \mathrm{C}$ & Oda sıcaklığı & $80^{\circ} \mathrm{C}$ \\
\hline $\begin{array}{l}\text { İçinde } \\
\text { kısa } \\
\text { süre } \\
\text { besin saklanan } \\
(\mathrm{N}=11)\end{array}$ & $\begin{array}{r}1 \\
2 \\
3 \\
4 \\
5 \\
6 \\
7 \\
8 \\
9 \\
10 \\
11\end{array}$ & $\begin{array}{l}z^{* *} \\
\overline{-} \\
- \\
\overline{-} \\
\overline{5.4} \\
2.6 \\
\overline{2.6}\end{array}$ & $\begin{array}{r}58 \\
1.0 \\
27.2 \\
1.0 \\
1.0 \\
12.0 \\
2.6 \\
34.6 \\
64.8 \\
15.0 \\
32.6\end{array}$ & $\begin{aligned} & \simeq 1.0 \\
& 0 \\
& \simeq 1.0 \\
& \simeq 1.0 \\
& 3.6 \\
& \simeq 1.0 \\
& 1.0 \\
& 3.0 \\
& 30.0 \\
& 1.0 \\
& 4.0\end{aligned}$ & $\begin{array}{r}42.4 \\
2.6 \\
230.4 \\
9.8 \\
27.0 \\
108.0 \\
8.8 \\
115.2 \\
96.8 \\
59.2 \\
86.8\end{array}$ & $\begin{array}{r}\simeq 1.0 \\
12.2 \\
- \\
1.0 \\
1.0 \\
1.1 \\
1.0 \\
42.5 \\
1.0 \\
8.7\end{array}$ & $\begin{array}{c}58 \\
\overline{64} \\
- \\
- \\
31.6 \\
1.4 \\
42.4 \\
96.0 \\
16.5 \\
60.4\end{array}$ \\
\hline $\begin{array}{l}\text { Sinır } \\
\text { Ortalama } \\
\text { Sd }\end{array}$ & & $0-5.4$ & $\begin{array}{r}1.0-64.8 \\
22.71 \\
\pm 22.95\end{array}$ & $\begin{array}{r}0-30.0 \\
4.24 \\
9.72\end{array}$ & $\begin{array}{r}2.6-230.4 \\
71.55 \\
\pm 66.95\end{array}$ & $\begin{array}{c}1.0-42.5 \\
6.30 \\
\pm 28.56\end{array}$ & $\begin{array}{r}0-96.0 \\
47.16 \\
\pm 31.76\end{array}$ \\
\hline $\begin{array}{l}\text { Içinde uzun süre besin } \\
\text { saklananlar }(\mathrm{N}=4)\end{array}$ & $\begin{array}{l}12 \\
13 \\
14 \\
15\end{array}$ & $\begin{array}{l}\overline{-} \\
2.6 \\
1.0\end{array}$ & $\begin{array}{r}2.0 \\
10.2 \\
72.0 \\
19.8\end{array}$ & $\begin{array}{l}- \\
1.0 \\
1.0 \\
2.0\end{array}$ & $\begin{array}{r}3.6 \\
48.4 \\
140.4 \\
48.4\end{array}$ & $\begin{array}{l}- \\
1.0 \\
1.0 \\
1.0\end{array}$ & $\begin{array}{r}1.0 \\
5.0 \\
85.0 \\
36.0\end{array}$ \\
\hline $\begin{array}{l}\text { Sinır } \\
\text { Ortalama } \\
\text { Sd }\end{array}$ & & $\begin{array}{r}0-2.6 \\
0.9\end{array}$ & $\begin{aligned} & 2.0-72.0 \\
& 26 \\
&+ 31.52 \\
&\end{aligned}$ & $\begin{array}{r}0-2.0 \\
1.0\end{array}$ & $\begin{array}{c}3.6-140.4 \\
60.2 \\
\pm 49.78 \\
\end{array}$ & $0-1.0$ & $\begin{array}{c}1.0-85.0 \\
31.7 \\
\pm 38.79\end{array}$ \\
\hline
\end{tabular}

* Sürel/2 saat

** miktar $0.5 \mu \mathrm{g} / \mathrm{ml}$ altında 
Tablo V. Polietilen, Polistiren polivinilklorür plastiklerinde total eter ekstraktı

\begin{tabular}{|c|c|c|c|}
\hline & \multicolumn{3}{|c|}{ Eter ekstraktı \% } \\
\cline { 2 - 4 } No & PE & PVC & PS \\
\hline 1 & 0.59 & 1.05 & 4.20 \\
2 & 10.30 & 0.96 & 4.42 \\
3 & 0.10 & 1.37 & 5.63 \\
4 & 0.88 & 1.00 & 6.77 \\
5 & 0.62 & 0.01 & \\
\hline Ortalama & 2.498 & 0.878 & 5.255 \\
Sd & \pm 4.371 & \pm 0.511 & \pm 1.189 \\
\hline
\end{tabular}

TARTIŞMA

1. Bu araştırmada, Türkiye'de besin ambalajı ve besin maddelerinin konulmasında kullanılan plastik kapların, başlıca PE, PS PVG ve melamin polimerlerinden oluştuğu saptanmiştır. Bunlar arasında PE tipi gerek kullanma yeri ve gerekse miktarı bakımından ön siradadır. Pet. Kim. A.Ş. den elde edilen bilgilere göre poliolefin (PE ve polipropilen), PVG ve 1975 yilındanberi de PS polimer kompaundları (ana maddeleri) yalnızca Pet. Kim. A.Ş. Yarımca kompleksinde üretilmektedir*.1976 üretiminde çeşitli amaçlar için üretilen plastik polimerlerinden PE miktarı 86000 ton ile (13000 ton YDPE ve 63000 ton ADPE şekli), PVG (53000 ton) ve PS'den (11000 ton) daha fazladır. Bu polimerlerin çeşitli amaçlara yönelik olarak işlenmesi ise plastik fabrika ve imalâthanelerinde gerçekleştirilmektedir. 1968 yılı plastik Sanayi Kataloğunda (30), tam olmadığı bildirilen, belgeli plastik işyerlerinin 750 tane olduğu, yine tam olmayan bilgilere göre besin ambalajı ve besin kabı olarak plastik işleyen, imalâthanelerin sayısı ise Türkiye'de 30 adet olarak bildirilmiştir**.

Melamin plastikleri ise ilk maddesinden itibaren plastik fabrikalarında yapılmaktadır. Katalogda belirtilen bir adrese karşın topladığımız melamin kapların taşıdığı ticari damgaya göre en az 12 tane imalâthane vardır.

Tablo I'in incelenmesinden anlaşılacağı üzere melamin plastikleri dışında incelenen 66 plastik kabın (PE, PS ve PVG) ancak 7 tanesi kalite veya imalâthane damgasını taşımaktadır.

* Pet. Kim. A.Ş. den elde edilen yazılı bilgi ve görüşmeler

** Türkiye Ticaret Odaları, Sanayi Odaları ve Ticaret Borsaları Birliğinden elde edilen bilgilere göre. 
Örnek olarak toplanan plastik maddeler polimer cinsi bak1mindan -belirli standardlara uymak koşulu ile- dış ülkelerde $(16,17)$ besin maddesi olarak müsaade edilenler arasındadır. Türkiye'de ise PE, PS ve melamin ve geçici olarak da PVC plastik kaplarının besin maddesi olarak kullanılmasına izin verilmiştir*.

2. Plastik kaplarda toksik metallerden $\mathrm{Pb}$ ve $\mathrm{Cd}$ tayini sonuçIarı ilginçtir (Tablo II). 14 adet PE besin kabında ortalama kurşun miktarı \% $270 \pm 697.5 \mu \mathrm{g}(2.7 \pm 6.98 \mathrm{ppm})$ saptanmıştır. Ayrı ayrı plastiklerde $\mathrm{Pb}$ miktarı ortalama değerden büyük farklılık göstermektedir. Örneğin yeşil renkli PE-İ. bidonda \% $2600 \mu \mathrm{g}$ gibi en yüksek değer yanında, ADPE tipinde yarı şeffaf plastik PE bardakta $\% 2.5 \mu \mathrm{g}$ gibi küçük bir değer saptanmıştır. Kurşun tuzları, plastiklerin zaman ve işık etkisiyle bozunmasına engel olmak için stabilizatör (1) olarak kullanılması ve boyar maddeler nedeni ile plastik kaplarda bulunabilir. Türkiye'de üretilen PE ve PS polimerlerinde Standard arama yöntemleri ile ağır metaller $(\mathrm{Pb})$ saptanmamıştır (7). Bu bilgilere göre, plastik kaplarda saptanan kurşun daha çok plastik madde işlenmesi sırasında kullanılan katkı maddeleriyle ilgili görülmektedir.

Besin kabından asitli ortamda geçen ( $\% 4$ asetik asit) $\mathrm{Pb}$ miktarı toksisite bakımından daha önemlidir. PE plastik kaplarda asitli çözeltiye geçen $\mathrm{Pb}$ miktarı ortalama $0.31 \pm 0.306 \mu \mathrm{g} / \mathrm{ml}(0.31 \pm 0.306$ ppm) bulunmuştur. 1970 yılında Dünya Sağlık Örgütü (31) içme suları için müsaade edilen maksimum kurşun miktarını $0.1 \mathrm{mg} / 1(0.1$ $\mathrm{ppm}$ ), Türk Standardları Enstitüsü (TSE) tarafindan ise bu değer 1972 yilında $0.05 \mathrm{mg} / 1(0.05 \mathrm{ppm})$ olarak saptanmıştır (32).

Polistiren plastik kaplarda saptanan ortalama kurşun miktarı $(\% 218.89 \pm 453.73 \mu \mathrm{g})$, PE eşya için bulunan değerden biraz daha düşük olmakla beraber asetik asitli suya geçen miktar çok daha yüksek $(0.99 \pm 1.57 \mu \mathrm{g} / \mathrm{ml})$ saptanmiştır. Bu durum $\mathrm{Pb}$ katyonunun PS plastiğinden daha kolay elüe olduğunu göstermektedir. Gerek PE ve gerekse PS plastik besin kaplarının asit özellikte sıvı besin maddeleri ile teması, organizmaya oral yol ile giren $\mathrm{Pb}$ miktarı için önemsenmeyecek bir kaynak olarak kabul edilebilir. Ancak 400-500 $\mu \mathrm{g} / \mathrm{gün}$ kurşunun tolere edilebileceği bildirilmektedir (33).

\footnotetext{
* S.S.Y.B. dan elde edilen bilgilere göre.
} 
Gd tuzları da stabilizatör olarak plastik yapımında kullanıldığı gibi (1), boyalar nedeni ile de plastik kaplarda bulunabilir (34). Gerek PE (ortalama Gd miktarı \% 26.9 $\pm 64.86 \mu \mathrm{g}$ ) ve gerekse PS kaplarda (ortalama Gd miktarı \% $31.48 \pm 33.09 \mu \mathrm{g}$ ) saptanan Gd miktarının ortalama değerden fazla farklılık göstermesi, katkı maddesi olarak plastikte kalan bu metalin imalâthane koşullarına bağlı olduğunu göstermektedir. Asetik asitli çözeltiye geçen Cd miktarı PE plastik kaplarında ortalama $0.06 \pm 0.04 \mu \mathrm{g} / \mathrm{ml}(0.06 \mathrm{ppm})$ ve PS de ise $1.1 \pm 0.1 \mu \mathrm{g} / \mathrm{ml}(1.1 \mathrm{ppm})$ saptanmıştır. Pb gibi Cd da PS plastiklerinden daha kolay elüe olmaktadır. Her iki tip plastik örneklerinde saptanan bu değer içme suları için kabul edilen maksimum limiti $(0.05 \mathrm{ppm})$ aşmaktadır (31). Son yıllarda Cd çevreden organizmaya giren kümülâtif ve ciadi toksik etkileri ile önemli bir metal olarak dikkati çekmektedir $(35,36)$. Dışarıdan alınmasına müsaade edilen günlük Gd miktarı 20-50 $\mu \mathrm{g}$ (37) olarak ön görülmektedir. Sonuçlara göre plastik besin kaplarından alınabilecek Cd miktarını bu kümülâtif zehirin organizmaya girmesinde önemli bir kaynak olabileceği açıktır.

3. Polistiren plastik kabında kloroforma geçen stiren monomer miktarı ortalama değerler bakımından ( $\% 262.81 \pm 272.65 \mathrm{mg})$ gerek besin maddeleri ile gerekse diğer besin maddeleri ile temas eden PS plastik kaplarda müsaade edilen stiren miktarının ( $\% 0.5$ ve $\% 1 \mathrm{~g}$ ) altındadır (16). En yüksek stiren miktarı 1 no'lu PS sürahide (\% $850 \mathrm{mg}: 8500 \mathrm{ppm}$ ) saptanmıştır. Bu bulgu, Japon araşt1rıcı TATSUNO ve KUROKI (38) nin plastik kaplarda tayin ettiği maksimum değerin (13000 ppm) çok altındadır.

Melamin plastiklerinden $80^{\circ} \mathrm{C}$ de nötral, asitli ve $\% 10$ alkollü çözeltiye geçen formaldehit miktarları kabul edilen sınırın çok üstünde saptanmıştır. Alman standardlarına göre (17) bu sınır $1 \mathrm{ppm}$ dir. Formaldehit asitli ortamda (ortalama $71.55 \pm 66.95 \mathrm{ppm}$ ) nötr $(22.71 \pm 22.95 \mathrm{ppm})$ ve alkollü çözeltiye (ortalama $47.16 \pm$ $31.76 \mathrm{ppm}$ ) göre daha çok geçmektedir. Yalnız 2 ve 12 No'lu örnekler hemen hemen standardlara uymaktadir. Oda isisinda ise, hemen çoğunda ekstrakte olan formaldehit miktarı müsaade sınırının altında veya biraz aşmakla beraber, standardlara göre ekstraksiyonun $80^{\circ} \mathrm{C}$ de yapılması önerilmektedir. İçinde, besinlerin uzun süre veya kısa süre bulundurulduğu kaplar için sonuç fazla fark göstermemektedir. 
(Tablo IV). Formaldehit gerek inhalasyon ve gerekse deri ve oral yolla organizmaya girdiğinde önemli toksik belirtiler gösteren irritan bir maddedir $(27,39)$.

4. PE, PS ve PVC plastiklerinde eter ekstraktı kabul edilen limit değerin $(\% \quad 0.3)$ üstünde saptanmıştır. Eter ekstraktı plastifiyan, yumuşatıcı, emülsifiyan gibi katkı maddelerini içermektedir (17). $\mathrm{Bu}$ miktarın yüksek olması çeşitli toksik katkı maddelerinin - $\mathrm{fta}-$ latlar $(40,41)$, fenol ve türevleri gibi, fotosensitizan maddeler (42) toksik düzeyde olabileceğini göstermesi açısından önemlidir.

\section{SONUÇ}

Besin maddelerinin ambalajı ve konulmasında kullanılan plastik kaplar polimer cinsi bakımından Türkiye ve dıs ülkelerce kullanılması kabul edilenler arasındadır. Ancak:

1- Bu maddelerin polimerleri belli bir standarda göre çalışmayan, imalâthanelerde işlenmektedir. Besin maddesi ile temasta olan plastik kapların besin çeşitlerine göre polimer yapısı, katkı maddelerinin cinsi ve miktarı bakımından özelliklerinin saptanması gerekir. İmalâthaneler bu standarda uygun olarak plastik maddeyi işlemelidir. Kaldı ki ülkemizde bir çok imalâthaneler ayrı yerde çeşitli amaçlara yönelik plastikleri fark gözetmeksizin işlemektedir. Diğer taraftan saptanan özelliklerin standard yöntemlerle araştrirlması gerekmektedir. TSE nün çeşitli plastikler için bazı standard yöntemleri varsa da (43) bu yeterli değildir.

2- Metalik zehirlerden $\mathrm{Pb}$ ve Cd incelediğimiz PE ve PS plastiklerinde, özellikle asit besin maddelere geçebilecek miktar, içme sularında müsaade edilen limiti aşmaktadır.

3- Melamin plastiklerinin çoğunda nötr, asitli veya alkollü ortamda geçen formaldehit miktarı yine müsaade sınırının çok üstünde olması, polimerizasyonun iyi olmadığını göstermekte ve sağlık için de kronik toksite açısından önemli düzeye ulaşmaktadır.

4- Nihayet eter ekstraktının PS, PE ve PVC plastiklerinde yüksek olması yağlı besinler için zararlı olabilir. Bu konudaki çalışmaların yeterli olmadığı ve devam etmesi gerektiği kanısındayız. 


\section{ÖZET}

Bu çalışmada Türkiye'de besin ambalajı ve konulmasında kullanılan plastiklerin polimer cinslerinin başlıca PE, PS, PVG ve melamin olduğu saptanmıştır. Polietilen besin kapları gerek çeşit ve gerekse miktar bakımından başta gelmektedir. Bunlardan PE (YDPE, ADPE ve PE-I), PS ve PVG polimer ana maddeleri yalnız Pet. Kim. A.Ş. Yarımca tesislerinde imal edilmektedir. Bu polimerlerin besin ambalaj ve kabı olarak işlenmesi, melamin plastiklerinin yapımı ise Türkiye'nin çeşitli yerlerindeki plastik fabrika ve imalâthanelerinde işlenmektedir.

PE ve PS plastik kaplarda ve bu kaplardan asite $(\% 4$ asetik asite) geçen çözeltide $\mathrm{Pb}$ ve $\mathrm{Cd}$ miktarı atomik absorbsiyon spektrofotometresi ile tayin edilmiştir. PE (ortalama: \% $270.2 \pm 697.5$ $\mu \mathrm{g} \mathrm{Pb}, \% 26.9 \pm 64.86 \mu \mathrm{g} \mathrm{Cd}$ ) ve PS'de (ortalama: \% $218.89 \pm$ $453.73 \mu \mathrm{g} \mathrm{Pb}, \% 31.48 \pm 33.09 \mu \mathrm{g} \mathrm{Cd})$ saptanan $\mathrm{Pb}$ ve $\mathrm{Cd}$ un ortalama değerden büyük fark göstermesi, polimerlerin işlendiği imalâthane çalışma koşullarına bağlıdır. Asitli ortama geçen $\mathrm{Pb}(0.31 \pm$ $0.306 \mathrm{ppm}$ PE de, $0.99 \pm 1.58 \mathrm{ppm}$ PS de) ve Cd $(0.06 \pm$ $0.04 \mathrm{ppm}$ PE de, $1.1 \pm 0.1 \mathrm{ppm}$ PS'de) miktarları içme suları için kabul edilen limiti $(0.1 \mathrm{ppm} \mathrm{Pb}, 0.05 \mathrm{ppm} \mathrm{Cd})$ aşmaktadır. Özellikle PS plastikleri ile elüe olan $\mathrm{Pb}$ ve $\mathrm{Cd}$ miktarları daha yüksek bulunmuştur.

16 PS plastik besin kabında gaz kromatografisi yöntemi ile tayin edilen stiren monomer miktarı ortalama $2620.8 \pm 2726.5 \mathrm{ppm}$ saptanmiş olup, gerek ortalama ve gerekse maksimum değer $(8500$ ppm) müsaade edilen limitin altındadır.

Melamin plastiklerinde spektrofotometrik yöntemle tayin edilen nötr, asitli ve \% 10 alkollü ortama geçen formaldehit miktarları $(22.71 \pm 22.95 \mathrm{ppm}$ nötr, $71.55 \pm 66.95 \mathrm{ppm}$ asitli, $47.16 \pm 31.76$ ppm alkollü ortamda) müsaade edilen limiti (1 ppm) çok aşmaktadir.

PE, PS ve PVG plastiklerinde eter ekstraktı (Tablo V) da standard değerlerin üstünde saptanmıştır.

Bu bulgularımız, Türkiye'de besin kabı ve ambalajı olarak çeşitli küçük plastik fabrika ve iş yerlerinde işlenen PE, PS ve PVG polimerlerinin ve melamin plastiklerinin belirli standardlara göre yapılması 
gerektiğini göstermektedir. Sağlık Bakanlığı tarafından hazırlanmakta olan plastik besin kapları için belirtilen özelliklere göre bu iş yerlerinin kontrolü ve değerlendirilmesinin büyük yararı olacağı kanısındayı.

\section{SUMMARY}

Plastic utensils used as food packages and containers in Turkey, are principally made of polyethylene (PE), polystyrene (PS), polyvinyl chloride (PVG) and melamine plastics. PE wares take the first place both in amount and both in variety. PE, PS and PVC polymer compounds are manufactured by Pet. Kim. Yarımca factory. The moulding and processing of these plastics are made in small plastic factories or manufactories which their total numbers are at least 50 .

$\mathrm{Pb}$ and $\mathrm{Cd}$ amounts are determined by atomic absorption spectrophotometry in $14(\mathrm{PE})$ and 11 (PS) plastic wares, as well as in acid solution (4\% acetic acid) migrated from the container into the acid. The mean results are $(2.7 \pm 6.98 \mathrm{ppm}$ as lead and $0.26 \pm 0.65 \mathrm{ppm}$ as cadmium) in PE plastics and $(2.18 \pm 4.54 \mathrm{ppm}$ as lead and $0.31 \pm 0.33 \mathrm{ppm}$ as cadmium) in PS plastics. $\mathrm{Pb}$ and Cd levels, migrated from container into acid solution found $(\mathrm{Pb}: 0.31 \pm$ $0.306 \mathrm{ppm}$ from PE, $0.99 \pm 1.58 \mathrm{ppm}$ from PS), $(\mathrm{Gd}: 0.06 \pm 0.04$ $\mathrm{ppm}$ from PE, $1.1 \pm 0.1 \mathrm{ppm}$ from PS) are higher than the maximum allowable concentration (MAC) for lead $(0.1 \mathrm{ppm})$ and for $\mathrm{Cd}$ $(0.05 \mathrm{ppm})$ in drinking water.

Styrene monomer determined by gas chromatograph in 16 PS plastic wares (mean $2620.8 \pm 2726.5 \mathrm{ppm}$ ) is below the MAC set by USA regulations.

Formaldehyde amounts migrated from 18 melamine plastic utensils into neutral, acid and \% 10 alcoholic solutions are determined by spectrophotometric method based on the colour reaction with chromotropic acid. The results are significantly higher than the MAG proposed by German (FDR) standards (1 ppm) all in these three conditions (in neutral solution: $22.71 \pm 22.95 \mathrm{ppm}$, in acid solution: $71.55 \pm 31.76 \mathrm{ppm}$ ).

The total ether extracts of PE, PS and PVG plastic wares are also higher than MAC (Table V). 
These results show that, manufacture of plastic food utensils should be strictly controlled according to the standards set by Health and Social Welfare Ministry and other associated organizations.

\section{TEŞEKKÜR}

Çalışmamda gerekli teknik bilgi, polimer ve stireni sağlayan Pet. Kim. A.Ş. Genel Md. ne; Atomik Absorbsiyon spektrofotometrelerinden yararlandığım Nükleer Araştırma ve Eğitim Merkezine; gaz kromatograflarından yararlandığım A.Ü. Fen F. Sinai ve Tatbiki Kimya Kürsüsü ilgililerine teşekkürü bir borç bilirim.

\section{LITERATÜR}

1. Malten, K. E., Zielhuis, R.L., Industrial Toxicology and dermatology in the production and processing of plastics. Elsevier, Amsterdam (1964).

2. Casarett, L.J., Doull, J., Toxicology The Basic Science of Poisons MacMillan Publishing Comp. Inc. New York (1975).

3. Vural, N., A.Ü.T $p p$ F.Mec. XVI, 310-318 (1963).

4. Jaeger, R.J., Rubin, R.J., Science, N.V., 170, 460 (1970).

5. Hıncal, F., Türk Hij. Den. Biyol. Derg. 36 (1), 108-21 (1976).

6. Cooper, J., Plastic Containers for pharmaceuticals Testing and Control. WHO, Geneva (1974).

7. İzü̈, E., Canefe, K., Doğa 1, 82-88 (1977).

8. Crouzet, C., Merchal, J., Makromol. Chem. 177, 2819-2832 (1976).

9. Hagen, E., Analyt. Abst. 18, No: 1054 (1970).

Ref: Plastic Kautsch. 15 (10), 711-713 (1968).

10. Caprino, L., Togna, G., Mazzei, M., European F. Toxicol. Environ. Hyg. 9 (2), 99-105 (1976).

11. Petrovskil et al, Gig. Sanit 34, 80-83 (1969 Oct.).

12. Mac Farland et al, Bull. Env. Cont. Toxicol. (U.S.A.) 6, 509 (1971).

13. Cavigneau, V., Cabasson, G.B., Fd Cosmet. Toxicol. 11 (1), 2462 (1973) Ref: Archs. Mal. Prof. Med. trav. 33, 115 (1972).

14. Mayer, L.F., Stalling, J., Johnson, İ, Nature, 138, 411-413 (1972).

15. Meri, S., J. Chromatog. 129, 53-60 (1976).

16. The Office of the Federal Register National Archives and Records Service; Code of federal regulations, Food and Drugs, Parts 120-129 U.S. Government Printing Office Washington (1972).

17. Franck, R., Mühlschlegel, H., Kunststoffe im Lebensmittel Verkehr Empfehlunger der Kunsstoff-Kommission des Bundesgesundheitamtes Textausgabe 18. Lieferung Stand 1. April 1974. Carl Heymanns Verlag K.G. Berlin (1974). 
18. Woggon, H., Uhde, J., Zydek, G., Z. Lebensmittelunters, u.-Forsch. 138 (3), 169-176 (1968).

19. Uhde, W.J. et al., Nahrung 20 (2); 185-94 (1976).

20. Wildbrett, G., Evers, K., Kiermeier, F., Z. Lebensmittelunters, u. Forsch., 137 (6), 356-362 (1968).

21. Figge, K., Fd. Cosmel. Toxicol. 10, No: 6, 815-828 (1972).

22. Sokolowska, R., Roczn. Panstw Zaki Hig 20, 383-389 (1969).

23. Stokes, B.J., Organic Chemistry S: 22-23, Edward Arnold Third Edition (1972).

24. Druchman, D., Atomic Absorption Newes Letter 6 (5) (1967).

25. FAO: Current Food Additives Legislation, GFAL, No: 76 Abstract No: 1113, (31, VII. 1964).

26. Chojnicka, B., Roczn. Panst W. Zaki Hig. 20, 585-594 (1969).

27. Kaye, S., Handbook of Emergency Toxicology II. Edition Charles C. Thomas Publisher, USA (1961).

28. Türk Farmakopesi 1974 S. 238, Sağlık ve Sosyal Yardım Bakanlığı, Sayı: 435, Milli Eğitim Basımevi, İstanbul (1974).

29. Sokolowska, R., Roczn. Panstw Zaki Hig. 20, 281-290 (1969).

30. Türkiye Ticaret Odaları, Sanayi Odaları ve Ticaret Borsaları Birliği: Türkiye Plastik Sanayi Kataloğu (1968).

31. WHO; European Standards for Drinking Water Second Edition, WHO, Geneva (1970).

32. Türk Standardla:ı Enstitüsü: İçme Suları TS 266 UDK 663-6: 543, Úçüncü Bask1, TSE, Ankara (1972).

33. Blokker, P.C.; Atmospheric Eniiron, 6, 1-18 (1972).

34. Friberg, L., Piscator, M., Nordberg, G., K jelström, T., Cadmium in the environment. 2 nd ed. GRC Press, Gleveland Ohio (1974).

35. Roels, H., Lau Werys, R., Bucket, J.P., Study on Cadmium Proteinuria-International Symposium: Environmental and Health No: 64, CEC-EPA-WHO Paris (June 1974).

36. Watanabe, H., Murayama, H., A study on health effect indices concerning population in cadmium polluted area CEC-EPA-WHO Paris (June 1974).

37. Webb, M., British Medical Bulletin, 31 (3), 246-250 (1973).

38. Tatsuno, T., Kuroki, T., Bull Natl. Ins. Hyg. Sci. (Tokyo), 89, 122-124 (1974).

39. Dubreuil, A., Bouley, G., Godin, J., Boudene, U., European f. Toxicol. Environ. Hyg. 9 (4), 245-250 (1976).

40. Abst no 2410: Softening the PVG blow Fd. Cosmet. Toxicol. 10 (5), 1972).

41. Srivastava, S.P., Agarwal, D.K., Kseth, P., Toxicology, 7, 163-168 (1977).

42. Gaprino, L., Togna, G., Mazzei, M., Europ. F. Toxicolog. Environ. Hyg. 9 (2), 99-105 (1976).

43. TSE: Türk Standardları Kataloğu, TSE, Necatibey cad. 112, Bakanlıklar ANKARA (1973). 